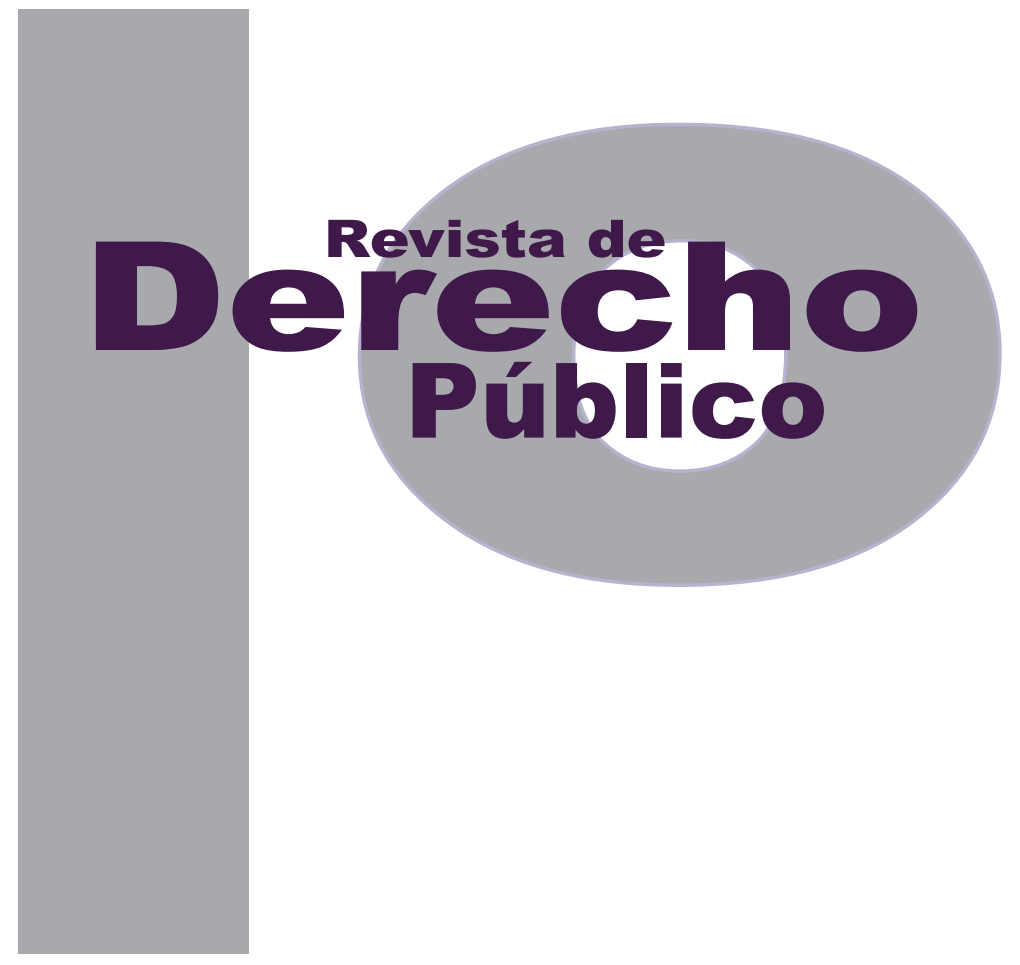

\title{
LA DELEGACIÓN LEGISLATIVA EN EL MARCO CONSTITUCIONAL VENEZOLANO
}

\author{
Ofelia Riquezes Curiel
}

Universidad de los Andes

Facultad de Derecho

Revista de Derecho Público N. ${ }^{\circ} 28$

Enero - Junio de 2012. ISSN 1909-7778 


\title{
La delegación legislativa en el marco constitucional venezolano
}

\author{
Ofelia Riquezes Curiel ${ }^{1}$
}

\section{RESUMEN}

A través del artículo se pretende describir las características de la delegación legislativa a la luz de la actual Constitución venezolana, y analizar el riesgo que representa la ausencia de estrictos límites a la actividad legislativa del poder Ejecutivo para la efectividad del principio constitucional de separación de poderes y, en consecuencia, para la preservación del Estado de derecho.

A tales fines, se ha dividido el trabajo en cuatro partes. La primera de ellas realiza una breve introducción del tema, al exponer la noción liberal del Estado de derecho y definir sus elementos,
The article is intended to describe the specific characteristics of delegated legislation within the current Venezuelan constitutional regime, and analyze the risk posed by the absence of strict limits to the legislative activity of the Executive Power, regarding the effectiveness of the constitutional principle of separation of powers and, consequently, the preservation of the ancient rule of law.

Attending to said purposes, the article is divided into four parts. The first of them makes a brief introduction in exposing the liberal notion of the rule of law, and defining its elements, among which is the known "organizing princi-

\footnotetext{
Abogada egresada Cum Laude de la Universidad Metropolitana, Caracas, Venezuela, en el año 2010. Luego de haberse dedicado a la prestación de asesoría jurídica a sectores de bajos recursos de Caracas, en el marco del proyecto TodoLegal, se desempeñó como abogada asociada en la firma Imery Urdaneta Calleja Itriago \& Flamarique, en el área de Derecho corporativo/internacional. Diplomados internacionales en Relaciones Internacionales y en Técnicas de Negociación y Resolución de Conflictos, avalados por el Centro UNESCO para la formación en Derechos Humanos, Ciudadanía Mundial y Cultura de Paz; la Universidad Internacional para Estudios Globales (Florida), y la Asociación de las Naciones Unidas en Venezuela. Actualmente forma parte de la Facultad de Estudios Jurídicos y Políticos de la Universidad Metropolitana, y es profesora titular de la asignatura Derecho de Personas en la mencionada institución.
} 
entre los cuales se encuentra el conocido "principio de organización", que implica la división del poder público en núcleos especializados de competencia.

En segundo lugar, se procede a desarrollar de forma más profunda el principio de la separación de poderes, y se señalan las consecuencias de su adopción en materia constitucional. Posteriormente, se estudia la figura de la delegación legislativa como matiz del mencionado principio, así como su fundamento teórico y los límites necesarios para su legitimidad.

Por último, se realiza una descripción de las particularidades que presenta la delegación legislativa en el marco constitucional venezolano, y se analizan las consecuencias de aquellas en relación con la vigencia del principio de organización como mecanismo de protección de los derechos de los ciudadanos ante el poder público.

Palabras clave: delegación legislativa, Venezuela, constitución, separación de poderes. ple", that involves the division of public power into specialized spheres of competence.

The second part of the article proceeds to a more profound study of the principle of the separation of powers, and to the outline of the implications of its adoption at the constitutional level. Later, the figure of delegated legislation is examined as a nuance of the abovementioned principle, as well as its theoretical basis and the necessary limits it must respect in order to maintain its legitimacy.

Finally, a description of the characteristics of delegated legislation within the current Venezuelan constitutional regime is made, as well as an analysis regarding their consequences in relation to the fulfilment of the principle of organization as a mechanism for the protection of citizen rights before the public power.

Keywords: delegated legislation, Venezuela, constitution, separation powers. 
SUMARIO

Introducción - I. EL PRINCIPIO DE LA DIVISIÓN DE PODERES - II. LA DELEGACIÓN LEGISLATIVA - III. LA DELEGACIÓN LEGISLATIVA EN EL MARCO CONSTITUCIONAL VENEZOLANO - IV. CONCLUSIONES - Bibliografía. 
Introducción

El Estado de derecho, concepto consolidado en el mundo occidental del siglo XIX, encuentra su fundamento en la necesidad de limitar el poder del Estado a través de un ordenamiento jurídico cuyo contenido es necesariamente independiente de la propia voluntad estatal, protegiendo así los derechos y libertades fundamentales del individuo. Nacido de las normas creadas a raíz de las grandes revoluciones del siglo XVIII, el Estado de derecho supone una noción típicamente liberal, y parte de la base de que el Estado tiene un fin último cuyo contenido está, no sólo en la ley, sino, en palabras de Kant, en

(...) los principios a priori de la libertad del hombre, de la igualdad del súbdito, de la autonomía del ciudadano, principios que no son tanto leyes dadas por el Estado ya instituido, sino condición para adaptar el Estado a los puros principios de la razón².

Tras siglos de permanencia del antiguo orden absolutista en el continente europeo, y especialmente a partir de la Revolución Francesa, se adoptó la visión del ser humano como principio y fin del Estado, y de la libertad como condición indispensable para el ejercicio de sus derechos. En el ámbito del constitucionalismo moderno, se ha superado la retrógrada y peligrosa noción de un poder público desmedido a través del establecimiento de diversos sistemas de leyes que lo limitan en favor de los intereses del ciudadano. Hoy en día, pues, la mayoría de los ordenamientos jurídicos a nivel mundial han aceptado que no son sólo los citados principios a priori los límites del poder del Estado, sino que, además, este último no puede sancionar acción alguna sino en virtud de una norma previamente establecida.

Schmitt ha señalado dos elementos típicos del Estado de derecho. El primero de ellos, denominado el "principio de distribución", se refiere a la libertad plena del individuo, limitada únicamente por la ley, frente a las facultades estrictamente restringidas del Estado ${ }^{3}$. El segundo de los elementos, el "principio de organización", cobra especial importancia a los efectos del presente análisis, pues conlleva la división del poder del Estado en esferas especializadas de competencia.

\section{EL PRINCIPIO DE LA DIVISIÓN DE PODERES}

El principio de la división de poderes, componente esencial para la configuración de un Estado de derecho, desarrollado principalmente por Locke y Montesquieu, establece la necesidad de dividir el Estado en diferentes organismos públicos autónomos que asumen funciones especializadas, y que ejercen un control recíproco de poder. Tal y como lo expresa Combellas:

La idea básica que guía al principio es la de que la mejor forma de limitar el poder estatal es el de dividirlo: el poder detiene al poder. Así

2 Kant, I. (1964). Acerca de la relación entre la teoría y la práctica en el derecho político (contra Hobbes). Buenos Aires: Nova. 
se asegura el despliegue de la libertad individual frente a los abusos del poder despótico ${ }^{4}$.

Ciertamente, la división de poderes obedece al interés superior de la tutela de los derechos individuales del ser humano, al instituir el comúnmente conocido sistema de frenos y contrapesos entre poderes públicos independientes $\mathrm{e}$ iguales entre sí, evitando de dicha forma todo tipo de extralimitaciones en el ejercicio de las facultades otorgadas al Estado por la ley. Se trata, pues, de un resultado de evolución histórica: la sociedad ha comprendido, tras largas épocas de injusticias y opresión, que lejos de bastar la mera consagración formal de derechos, debía erigirse una estructura capaz de garantizarlos.

La división tripartita de poderes, teoría cuyas raíces radican en las ideas del inmortal Aristóteles, pero formalmente planteada por Montesquieu, y acogida tradicionalmente por los países de tendencia liberal, introduce tres figuras fundamentales del Estado moderno: Ios poderes Legislativo, Ejecutivo y Judicial, que corresponden, respectivamente, a la división del ejercicio del poder en tres etapas: la legislación, la ejecución o gobierno, y la jurisdicción.

Siguiendo el planteamiento de La Roche, quien adopta a su vez la teoría de Esmein, se entiende que todo acto mediante el cual el gobierno dirige a un grupo social hacia un determinado sentido "se inicia cuando surge una orden del Poder y remata cuando el ciudadano la cumple, tiene lógicamente tres momentos o fases: el momen-

4 Combellas, R. (1990). Estado de Derecho: Crisis y Renovación. Caracas: Editorial Jurídica Venezolana. to de la Ley, el momento del acto ejecutivo y el momento de la discusión judicial" 5 .

El poder Legislativo, entonces, constituido generalmente por cuerpos deliberantes con potestad consultiva, surge como una primera rama del poder público, que se circunscribe a la actividad de trazar las normas generales que regirán la conducta de la sociedad. El poder Ejecutivo, a su vez, desarrolla la facultad de aplicar la ley y velar por su cumplimiento, y es responsable así de la gestión diaria del Estado. El poder Judicial se ejerce a través de la interpretación de las normas jurídicas generales y de su aplicación a casos concretos. Sin embargo, el presente estudio se centrará sobre la relación entre las primeras dos manifestaciones del poder.

El Barón de Montesquieu esboza diversas consideraciones que sustentan la necesidad de la división de poderes entre diversos titulares. Una de ellas precisamente resalta la importancia de la separación del poder Legislativo y el poder Ejecutivo, estableciendo el filósofo que, de no verificarse tal supuesto, se corre el peligroso riesgo de la emisión de normas "tiránicas" por parte de un monarca que las ejecutará del mismo modo 6 .

De la adopción de esta teoría como elemento fundamental para la existencia del Estado de derecho, y particularmente de la separación entre los poderes Legislativo y Ejecutivo, se derivan

5 La Roche, H. (1991). Derecho Constitucional. Tomo I (Parte general). Valencia: Vadell Hermanos Editores.

6 Montesquieu, C. (2003). Del espíritu de las leyes. Madrid: Editorial Alianza. 
diversas consecuencias; dos de ellas expuestas por La Roche de la siguiente forma:

a. Que el Poder Ejecutivo no puede, mediante decretos o reglamentos, suspender, modificar o derogar una Ley que rija en el Estado. Jurídicamente está incapacitado el Poder Ejecutivo para dictar, modificar o suspender cualquier Ley, y eso se explica teóricamente por cuanto la función primordial que corresponde al Poder Legislativo radica en la formulación de la Ley; y si el Poder Ejecutivo invade la órbita de acción del otro, incurre en una extralimitación de funciones, haciéndose reo de sanciones que la misma Constitución establece.

b. El Poder Ejecutivo no puede mediante decretos o reglamentos regular materias que corresponden específicamente al Poder Legislativo ${ }^{7}$.

Si bien es cierto que la división de poderes ha configurado un dogma constitucional adoptado por la mayoría de los países a nivel mundial, y que, tal y como se ha expuesto, resulta imprescindible para la garantía de derechos individuales frente al ejercicio del poder del Estado, ha sufrido en la práctica un proceso de transformación. La visión de La Roche sobre la separación de los poderes Ejecutivo y Legislativo, si bien acertada en principio, podría considerarse, desde el punto de vista de la tendencia constitucional moderna, un tanto radical. Ciertamente, la actividad legislativa del poder Ejecutivo constituye una irregularidad jurídica, partiendo de la estricta base de la división de poderes planteada por Montesquieu. Sin embargo, el proceso evolutivo que ha experimentado dicha teoría desde su creación en el siglo XVIII hasta nuestros días, ha generado la noción de poderes públicos que, si bien se encuentran divididos funcionalmente, cooperan entre sí para agilizar la gestión del Estado, y evitar así el colapso de un sistema de núcleos inconexos.

\section{LA DELEGACIÓN LEGISLATIVA}

Como consecuencia de dicha tendencia de cooperación entre poderes, se ha verificado lo que Combellas llama "la crisis del Parlamento", que no es más que el fin del monopolio del poder Legislativo sobre la actividad normativa. Tal y como lo indica el reconocido autor:

La delegación legislativa se ha convertido en una institución reconocida por todas las constituciones modernas (sea en el texto, sea en la praxis), a partir del período de entreguerras. Junto a ella, otra institución que ha cobrado significativa importancia en los tiempos actuales, es la de los decretos-leyes, creados como institución legislativa en circunstancias de naturaleza imprevisible, necesaria o urgente $^{8}$.

La inclusión a nivel constitucional de la posibilidad excepcional del ejercicio de la actividad legislativa por parte del poder Ejecutivo, lejos de implicar una renuncia a la división tradicional de los poderes, introduce un matiz: la cooperación de los diferentes órganos autónomos del 
Estado en favor de una gestión más eficiente de la Administración Pública, y el consecuente logro de su fin último: el bienestar del ciudadano.

La delegación legislativa reconoce su fundamento en la creciente capacidad del Ejecutivo para regular situaciones rápidamente cambiantes. Dicho supuesto se verifica, particularmente, durante situaciones irregulares de urgencia, pues el órgano legislativo por lo general no posee el alto grado de pericia necesaria para la toma de ciertas decisiones estatales. En consecuencia, la delegación legislativa al poder Ejecutivo no implica necesariamente el incurrimiento de este último en una extralimitación de funciones, sino que posibilita su contribución al cumplimiento de la primera etapa del acto de gobierno: la legislación.

Es menester destacar que, en virtud de la necesidad inicial de la separación de poderes, que conlleva precisamente la atribución de competencias estatales a titulares distintos y autónomos, la delegación legislativa debe ser siempre un evento excepcional, sujeto a estrictas normas que impidan la confusión de funciones de dos ramas independientes del Estado, y, más grave aún, la materialización del peor escenario planteado por Montesquieu: la ejecución tiránica de normas tiránicas. Si bien el Estado de derecho es totalmente normativizado, cuya actividad debe desarrollarse en estricto apego a un marco jurídico previamente establecido, las normas que componen este último suponen una normalidad de condiciones, o al menos, el mantenimiento de los supuestos de hecho vigentes al momento de su creación. Sin embargo, en ocasiones, la alteración temporal de las condiciones regulares de la sociedad genera la inaplicabilidad de la ley y por tanto requiere de medidas excepcionales. En palabras de Cortés:

\begin{abstract}
El legislador que en tiempos de disturbios y trastornos aspira a gobernar con las leyes comunes es un imbécil, el que aún en tiempos de disturbios y trastornos aspire a gobernar sin ley es temerario. El Derecho común es la regla ordinaria de los hombres en tiempos bonancibles. El derecho excepcional es su regla común en circunstancias excepcionales ${ }^{9}$.
\end{abstract}

El derecho excepcional, entonces, únicamente debe aplicarse mientras persista la situación irregular que encuadra en el marco de la ley. En este orden de ideas, la tesis general adoptada por la doctrina sostiene que los poderes legislativos extraordinarios delegados al poder Ejecutivo ciertamente pertenecen al derecho excepcional, pues, en condiciones normales que por su naturaleza no requieren de una respuesta urgente del Estado, la actividad normativa está circunscrita dentro del ámbito de competencias del poder Legislativo.

Siguiendo la tesis expuesta por García-Pelayo, para la verificación de un caso excepcional se requieren dos elementos: el primero de ellos se refiere al carácter anormal de la nueva situación; mientras que el segundo consiste en la temporalidad del cambio, pues, en caso contrario, "nos encontramos ante un cambio general de supuestos que no engendra un derecho ex-

9 Cortés, Juan D. (1904). "Proyecto de ley sobre estados excepcionales, presentado a las últimas Cortes por el ministerio de diciembre" en Obras completas. Madrid: Imprenta de Tejado. 
cepcional por su naturaleza y por el tiempo de su duración, sino un nuevo Derecho general" ${ }^{10}$.

En virtud de lo anterior, la mayoría de las constituciones modernas que prevén la figura de la delegación legislativa consagran también una serie de juiciosas normas que imposibilitan el ejercicio regular de la actividad normativa por parte del poder Ejecutivo y, sobre todo, aseguran la preeminencia del órgano legislativo como autoridad competente en la materia. La doctrina emanada de diversos autores que han tratado el tema bajo estudio, considerada en conjunto, tiende a indicar que los ordenamientos jurídicos deben imponer al menos tres límites a la excepcional potestad legislativa del poder Ejecutivo, y se refieren, respectivamente, a: (i) la temporalidad de la delegación, (ii) las materias de reserva legal, y (iii) el rango de las normas emitidas.

El primero de los aludidos límites, referido a la temporalidad de la delegación legislativa, responde a la irregularidad transitoria de las circunstancias que justifican el ejercicio de la actividad normativa por parte del poder Ejecutivo. Tal y como se expuso con anterioridad, la delegación legislativa debe necesariamente tener un carácter excepcional, por cuanto su fin último consiste precisamente en la provisión de una respuesta rápida y eficiente del Estado, en situaciones temporales de urgencia. Una vez recuperada la normalidad de condiciones de la sociedad, la vigencia de la delegación legislativa pierde todo sentido, y su prolongación indefinida en el tiempo provocaría no sólo el incurrimiento

10 García-Pelayo, M. (1951). Teoría de la Constitución. Madrid: Manuales de la Revista de Occidente. del poder Ejecutivo en la extralimitación de funciones señalada por La Roche ${ }^{11}$, sino, en líneas generales, el quebrantamiento absoluto del principio de la división de poderes.

Un principio fundamental derivado del Estado de derecho es el de la reserva legal, que sostiene que ciertas materias podrán ser reguladas únicamente mediante una ley formal, es decir, aquella emanada del órgano colegiado al cual la Constitución ha conferido la competencia normativa. Este último, siguiendo tal principio, no podrá delegar a ningún otro órgano del poder público la legislación de las materias consideradas de reserva legal, que generalmente se refieren a todo tipo de limitaciones o restricciones a los derechos y garantías constitucionales. Casal justifica la importancia del respeto a la reserva legal "en virtud del principio democrático y del papel que según la teoría y los fundamentos del Estado constitucional incumbe al órgano deliberante y representativo en relación con los derechos inherentes a la persona" ${ }^{12}$. En consecuencia, tal y como lo afirma Brewer-Carías, la delegación de facultades normativas no puede abarcar materias que sean reservadas constitucionalmente al poder Legislativo, por referirse al régimen relativo a los derechos y garantías fundamentales del ser humano ${ }^{13}$. Tomando en cuenta, pues, el descrito principio de reserva legal y el carácter excepcional de la delegación

11 La Roche, H. Ob. cit.

12 Casal Hernández, J.M. (2006). Los derechos humanos y su protección. Estudios sobre derechos humanos y derechos fundamentales. Caracas: Universidad Católica Andrés Bello.

13 Brewer-Carias, A.R. (2001). Reflexiones sobre el constitucionalismo en América. Caracas: Editorial Jurídica Venezolana. 
legislativa, resulta necesaria, a fines de garantizar el despliegue de los derechos del individuo, la delimitación expresa de las materias cuya regulación se delegará al poder Ejecutivo.

Por cuanto la función del poder Legislativo consiste precisamente en dictar las normas que regirán, no sólo el comportamiento de la sociedad, sino también las actividades del poder público, la delegación legislativa puede realizarse únicamente mediante la promulgación de una ley formal ("ley habilitante"), que tenga por objeto otorgar una autorización excepcional y temporal al poder Ejecutivo para el ejercicio de la actividad normativa, dentro de los parámetros en ella establecidos. Considerando el conocido principio de jerarquía normativa introducido por el tratadista austríaco Hans Kelsen ${ }^{14}$, debe concluirse que aquellos decretos dictados en ejercicio del mandato conferido por una ley, deben necesariamente gozar de un rango idéntico o menor al de esta última, pues, de lo contrario, la autorización otorgada por el órgano legislativo, además de ser desmedida, podría provocar la imposición de leyes para cuya promulgación se exigen constitucionalmente mayores requisitos (tales como la consulta pública o el voto favorable de un mayor número de diputados), y la modificación de postulados y principios generales del ordenamiento jurídico en cuestión. En otras palabras, las normas dictadas bajo expresa autorización de una ley, únicamente pueden tener, según los postulados básicos de la lógica jurídica, la misma fuerza de dicha ley, o una inferior. Las posibles consecuencias de la transgresión

14 Kelsen, H. (1982). Teoría pura del derecho. México, D.F.: Universidad Nacional Autónoma de México. de este particular límite a la delegación legislativa serán más ampliamente ilustradas posteriormente, a la luz del régimen constitucional venezolano.

\section{LA DELEGACIÓN LEGISLATIVA EN EL MARCO CONSTITUCIONAL VENEZOLANO}

Tras la incorporación de la delegación legislativa en diversos ordenamientos jurídicos europeos, a fines de atender las situaciones de urgencia generadas por las guerras mundiales del siglo XX, $y$, particularmente considerando los efectos de la segunda de ellas sobre Venezuela, el primer mandatario Isaías Medina Angarita propuso la inclusión de una nueva facultad del Presidente de la República para dictar medidas extraordinarias en materia económica y financiera, previa aprobación del extinto Congreso Nacional, en la reforma constitucional de 1945.

En efecto, la Constitución Nacional ${ }^{15}$, reformada en dicho año, contemplaba, en el numeral vigésimo noveno de su artículo 104, entre las atribuciones del entonces Presidente de los Estados Unidos de Venezuela, la potestad de este último para “Ejercer en los términos que fije el Congreso la facultad de dictar medidas extraordinarias destinadas a proteger la vida económica y financiera de la Nación cuando la necesidad o la conveniencia pública lo requieran". Por primera vez, entonces, se introdujo la figura de la delegación legislativa en el país, mediante una disposición que hacía especial énfasis en el

15 Gaceta Oficial N 131 extraordinaria del 5 de mayo de 1945 
carácter excepcional de la misma, en la delimitación de las materias delegables, y en la obligatoria sujeción del Presidente a los términos fijados por el órgano legislativo.

Tras los diversos cambios acaecidos en la realidad y en el régimen constitucional venezolano, especialmente concluido el período dictatorial del General Marcos Pérez Jiménez, finalmente se promulgó la Constitución de la República de Venezuela en $1961^{16}$, que tuvo una vigencia de treinta y ocho años, y que recuperó la figura de la delegación legislativa, al incluir una disposición muy similar al precitado artículo de la reforma constitucional de 1945.

Así pues, la Constitución de 1961 establecía, entre las atribuciones del Presidente de la República, la potestad de "dictar medidas extraordinarias en materia económica o financiera cuando así lo requiera el interés público y haya sido autorizado para ello por ley especial" (numeral octavo del artículo 190). Dicha norma, al igual que su aludida antecesora, imponía ciertas restricciones a la delegación legislativa, especialmente referidas al carácter taxativo de las materias delegadas, a la excepcionalidad de las condiciones que justificaban dicha medida, y a la promulgación de una ley especial como requisito formal del otorgamiento de la autorización al Presidente de la República para ejercer la actividad normativa.

La Constitución de la República Bolivariana de Venezuela (CRBV), sancionada en el año

16 Gaceta Oficial №662 extraordinaria del 23 de enero de 1961.
$1999^{17}$, por contraste, prevé una delegación legislativa de la Asamblea Nacional en el Presidente de la República, cuya sorprendente amplitud, tal como lo afirma Brewer-Carías "no tiene precedentes en el constitucionalismo contemporáneo"18. El octavo numeral del artículo 236 de la Carta Magna vigente incluye, como una atribución del Presidente o Presidenta de la República, el "Dictar, previa autorización por una ley habilitante, decretos con fuerza de ley". El artículo 203 ejusdem indica, por su parte, que

Son leyes habilitantes las sancionadas por la Asamblea Nacional por las tres quintas partes de sus integrantes, a fin de establecer las directrices, propósitos y marco de las materias que se delegan al Presidente o Presidenta de la República, con rango y valor de ley. Las leyes habilitantes deben fijar el plazo de su ejercicio.

Dichas disposiciones constitucionales contemplan la delegación legislativa al poder Ejecutivo sin establecer más límites que (i) la formalidad de su verificación (pues necesariamente debe realizarse mediante ley habilitante), (ii) el rango máximo del que pueden gozar los decretos dictados por el Presidente o Presidenta de la República, en virtud de dicha autorización (al limitar la potestad normativa del Ejecutivo a la emisión de "decretos con fuerza de ley"), y (iii) la fijación del plazo del ejercicio de la ley habilitante. El constituyente venezolano de 1999 no sólo omitió la mención de límites necesarios para evitar la regularidad de la actividad legislativa del Presidente o Presidenta de la República,

17 Gaceta Oficial N³6.860 del 30 de diciembre de 1999.

18 Brewer-Carías. Ob. cit. 
sino que promovió dicha anomalía al suprimir intencionalmente los límites previstos por la Constitución de 1961 referidos a la irregularidad de condiciones que justifican la delegación legislativa y a la delimitación taxativa de las materias delegables.

La referida ausencia de restricciones que, en acertadas palabras de Brewer-Carías, podría resultar, y de hecho ha resultado, en un "atentado inadmisible" en contra del principio constitucional de la reserva legal ${ }^{19}$, ha sido aprovechada en la práctica por la Asamblea Nacional en la emisión de tres leyes habilitantes ${ }^{20}$ mediante las cuales se ha delegado al Presidente de la República la potestad de normar una vasta gama de materias, sin requisito circunstancial alguno. Si bien dichas normas han establecido un límite de tiempo para la actividad legislativa del poder Ejecutivo, éste ha sido fijado de manera arbitraria, por cuanto no ha correspondido a una alteración de las condiciones regulares de la sociedad venezolana.

Especial mención merece la vigente Ley que Autoriza al Presidente de la República Para Dictar Decretos con Rango, Valor y Fuerza de Ley en las Materias que se le Delegan, promulgada en el año $2010^{21}$. Considerando que la CRBV ha dejado a libre discreción del legislador la delimitación de las materias delegadas, mediante la mencionada ley se ha conferido al poder

19 Ibídem.

20 Publicadas, respectivamente, en la Gaceta Oficial № 37.076 del 13 de noviembre de 2000, № 38.617 del 1 de febrero de 2007, y № 6.009 extraordinaria del 17 de diciembre de 2010.

Gaceta Oficial № 6.009 extraordinaria del 17 de diciembre de 2010.
Ejecutivo la potestad de regular una totalidad de nueve amplísimos ámbitos, que incluyen, entre otros: la seguridad y defensa de la nación, la vivienda y hábitat, la cooperación internacional, el manejo de armas y elementos conexos, el sistema socioeconómico del país, finanzas y tributos, la prestación de servicios públicos, la ordenación territorial y la seguridad ciudadana y jurídica. Dentro de estas últimas secciones se prevé incluso la facultad del Presidente de la República para la imposición de nuevas sanciones para los hechos punibles tipificados por la normativa penal nacional, y para el diseño de una nueva regionalización geográfica del país, atendiendo siempre a los ideales de "justicia social e independencia económica". De tan vaga redacción se evidencia la ausencia de límites materiales de la delegación legislativa y la ausencia de un propósito concreto que la justifique. El Presidente de la República ha quedado facultado, pues, para normar prácticamente todo ámbito cuya regulación ha sido atribuida al cuerpo legislativo por la Constitución, y posteriormente, para ejecutar los decretos emitidos, quedando el ordenamiento jurídico venezolano de rodillas ante la voluntad de un único individuo cuyas funciones originarias nada tienen que ver con la legislación.

La ley, principal fuente del Derecho y requisito esencial para la convivencia humana, únicamente cumplirá tal objetivo en la medida que su contenido emane de la voluntad popular $y$, en consecuencia, represente el consenso de la sociedad sobre los patrones de conducta necesarios para el logro del bien común. Es precisamente por ello que el poder Legislativo 
es ejercido generalmente por un órgano deliberante compuesto por representantes de diversos sectores, electos mediante el sufragio. Mal podría denominarse "ley", pues, la simple imposición de un determinado comportamiento por parte de aquellos que ostentan la fuerza. No constituyendo los decretos con fuerza de ley, en este caso, una manifestación inequívoca del consenso de la sociedad venezolana, sino muy por el contrario, la mera exteriorización de una ideología individual, no sometida a controles ni debates, posibilitan ampliamente la promulgación de normas que colinden con las disposiciones y el espíritu del resto del ordenamiento jurídico, o que incluso, evaluadas aisladamente, carezcan de todo sentido.

Tal ha sido el caso de varios de los numerosos decretos-leyes emitidos por la Presidencia de la República durante el presente período constitucional, que, vale la pena destacar, según indica Pérez Perdomo, configuran aproximadamente un tercio de las piezas legislativas producidas durante los primeros diez años del actual gobierno de Hugo Chávez Frías ${ }^{22}$. Quizás el mejor ejemplo práctico del supuesto bajo estudio sea el Decreto con Rango, Valor y Fuerza de Ley del Sistema Nacional de Inteligencia y Contrainteligencia, dictado por el Presidente Chávez, en Consejo de Ministros, y publicado efectivamente en el año $2008^{23}$.

22 Pérez Perdomo, R. (2009). Derecho y cultura jurídica en Venezuela en tiempos de revolución (1999-2009). Caracas: Fundación Manuel García Pelayo.

Gaceta Oficial № 38.940 del 28 de marzo de 2008.
Bautizado popularmente como la "Ley Sapo", el Decreto con Rango, Valor y Fuerza de Ley del Sistema Nacional de Inteligencia y Contrainteligencia incluía, en sus escasos veintinueve artículos, atentados flagrantes en contra de diversas disposiciones constitucionales. La Ley Sapo no sólo colocaba a todos los venezolanos al servicio de la inteligencia del Estado, a fines de detectar de forma preventiva las "posibles amenazas" en su contra, sino que, además, imponía severas penas a aquellos ciudadanos que incumplieran los deberes inherentes a tal función, y violentaba la garantía constitucional del debido proceso al otorgar ventajas probatorias a los integrantes del Sistema Nacional de Inteligencia y Contrainteligencia, dentro de los procedimientos penales relacionados con la Ley.

Consecuentemente, la Ley Sapo, lejos de ser la expresión del consenso de la sociedad venezolana, enfrentó duras críticas de parte de numerosos sectores, y generó un elevadísimo nivel de polémica que giraba, principalmente, en torno a la constitucionalidad de sus disposiciones. El Presidente Chávez, habiendo improvisado y defendido un Decreto escandalosamente violatorio de derechos humanos fundamentales, y a todas luces contrario a los valores consagrados por la CRBV, se vio forzado a anunciar públicamente su derogatoria, sólo dos semanas tras la publicación en la Gaceta Oficial, admitiendo expresamente su inconstitucionalidad ${ }^{24}$.

Como si la ausencia de límites constitucionales a la delegación legislativa fuera poco, se

24 CNN Expansión. (2008). Chávez deroga ley de inteligencia. Obtenido el 10 de agosto de 2011 de http://www.cnnexpansion.com/ actualidad/2008/06/10/chavez-deroga-ley-de-inteligencia. 
ha incumplido además, en la práctica, uno de aquellos que sí ha sido establecido expresamente por la Carta Magna: el rango de los decretos emitidos por el poder Ejecutivo en ejercicio de la ley habilitante. Si bien el citado texto constitucional reza que dichos decretos podrán tener únicamente rango y fuerza de ley ordinaria, y aun cuando la exposición de motivos de la Carta Magna enumera de forma taxativa las leyes a las que puede conferirse el carácter de orgánicas, excluyendo de dicha enumeración a las leyes habilitantes, la Sala Constitucional del Tribunal Supremo de Justicia ha sostenido erróneamente que dichas leyes, por el simple hecho de encontrarse reguladas dentro del mismo artículo que menciona las leyes orgánicas, recibe automáticamente dicho carácter, y procede la Sala a concebir incluso la posibilidad de la emisión de "decretos con rango y fuerza de ley orgánica” ${ }^{25}$. Tal criterio, además de conllevar un incumplimiento absoluto del límite constitucional impuesto a la delegación legislativa, y contradecir abiertamente la voluntad del constituyente de 1999, ignora la finalidad propia de las leyes habilitantes. Las leyes orgánicas, según indica el artículo 203 de la Constitución, tendrán tal carácter en la medida que desarrollen derechos fundamentales, organicen los poderes públicos, o sirvan de marco normativo a otras leyes. Por cuanto la delegación legislativa surge como una medida excepcional fundamentada en la necesidad de emisión de normas concretas que regulen una situación de urgencia, difícilmente tendría sentido dictar un decreto de

25 Sentencia N 1716 del 19 de noviembre de 2001, referida a la revisión constitucional del Decreto con fuerza de Ley Orgánica de los Espacios Acuáticos e Insulares de 2001. rango orgánico en tales supuestos. El objetivo, en tal situación, jamás será establecer un marco normativo para otras leyes, sino actuar de forma rápida y eficiente para restaurar la regularidad de las circunstancias nacionales.

Haciendo caso omiso de lo anterior, la precitada Ley que Autoriza al Presidente de la República Para Dictar Decretos con Rango, Valor y Fuerza de Ley en las Materias que se le Delegan, en su segundo artículo, contempla expresamente la facultad del Presidente o Presidenta de la República para conferir el carácter orgánico a un decreto dictado en ejercicio de dicha ley habilitante, indicando también la obligatoriedad del sometimiento del decreto en cuestión a un control de constitucionalidad ejecutado por la Sala Constitucional del Tribunal Supremo de Justicia. Sin embargo, mientras la sanción de una ley habilitante requiere únicamente del voto aprobatorio de las tres quintas partes de los integrantes de la Asamblea Nacional, la sanción de las leyes orgánicas requiere la aprobación de las dos terceras partes de ellos (artículo 203, CRBV). En consecuencia, la promulgación de un decreto con rango y fuerza de ley orgánica, dictado en ejercicio de una ley habilitante, no sólo presentaría vicios de inconstitucionalidad, al no cumplir con el voto favorable del quórum del órgano legislativo requerido, sino que, además, permitiría la comisión de un fraude legislativo.

\section{CONCLUSIONES}

En consecuencia, lejos de tratarse en este caso de una colaboración entre dos ramas del poder público para la provisión de una respuesta 
rápida en situaciones de urgencia, se ha aceptado a nivel constitucional, en Venezuela, la posibilidad del ejercicio de una amplísima actividad normativa del poder Ejecutivo, aún en condiciones regulares, abriéndose el camino a la confusión de dos ramas de poder independientes, y, en consecuencia, a la transgresión del principio de separación de poderes establecido por la Carta Magna. Por consiguiente, tal y como se estableció anteriormente, la delegación legislativa carece de todo sentido mientras perdure la normalidad de condiciones de la sociedad, y, aun cuando esté justificada por alguna irregularidad, debe encontrarse estrictamente limitada a favor de la protección de los derechos y garantías individuales. El escenario planteado por la Constitución venezolana actual fácilmente podría dar paso, como de hecho lo ha dado, a la materialización de los peores miedos de Montesquieu: la debilitación del Estado de derecho, y aún más gravemente, al abandono del ciudadano frente a un poder tiránico que ha logrado acumular dos funciones estatales independientes.

\section{Bibliografía}

Brewer-Carías, A.R. (2001). Reflexiones sobre el constitucionalismo en América. Caracas: Editorial Jurídica Venezolana.

Casal Hernández, J.M. (2006). Los derechos humanos y su protección. Estudios sobre derechos humanos y derechos fundamentales. Caracas: Universidad Católica Andrés Bello.
CNN Expansión. (2008). Chávez deroga ley de inteligencia. Obtenido el 10 de agosto de 2011 de http://www.cnnexpansion.com/actualidad/2008/06/10/ chavez-deroga-ley-de-inteligencia.

Combellas, R. (1990). Estado de Derecho: Crisis y Renovación. Caracas: Editorial Jurídica Venezolana.

Cortés, Juan D. (1904). Proyecto de ley sobre estados excepcionales, presentado a las últimas Cortes por el ministerio de diciembre, en Obras completas. Madrid: Imprenta de Tejado.

García-Pelayo, M. (1951). Teoría de la Constitución. Madrid: Manuales de la Revista de Occidente.

Kant, I. (1964). Acerca de la relación entre la teoría y la práctica en el derecho político (contra Hobbes). Buenos Aires: Nova.

Kelsen, H. (1982). Teoría pura del derecho. México, D.F.: Universidad Nacional Autónoma de México.

La Roche, H. (1991). Derecho Constitucional. Tomo I (Parte general). Valencia: Vadell Hermanos Editores.

Montesquieu, C. (2003). Del Espíritu de las Leyes. Madrid: Editorial Alianza.

Pérez Perdomo, R. (2009). Derecho y cultura jurídica en Venezuela en tiempos de revolución (1999-2009). Caracas: Fundación Manuel García Pelayo. 
Schmitt, C. (1996). Teoría de la Constitución. Madrid: Editorial Alianza.

Normas y sentencias

Estados Unidos de Venezuela. Constitución Nacional de los Estados Unidos de Venezuela. Gaceta Oficial N131 extraordinaria del 5 de mayo de 1945.

República de Venezuela. Constitución de la República de Venezuela. Gaceta Oficial N ${ }^{\circ}$ 662 extraordinaria del 23 de enero de 1961.

República Bolivariana de Venezuela. Constitución de la República Bolivariana de Venezuela. Gaceta Oficial N 36.860 del 30 de diciembre de 1999.
República Bolivariana de Venezuela. Decreto con Rango, Valor y Fuerza de Ley del Sistema Nacional de Inteligencia y Contrainteligencia. Gaceta Oficial № 38.940 del 28 de marzo de 2008.

República Bolivariana de Venezuela. Ley que Autoriza al Presidente de la República para Dictar Decretos con Rango, Valor y Fuerza de Ley en las Materias que se le Delegan. Gaceta Oficial № 6.009 extraordinaria del 17 de diciembre de 2010.

República Bolivariana de Venezuela. Sala Constitucional del Tribunal Supremo de Justicia. Sentencia № 1716 de 19 de noviembre de 2001. 